
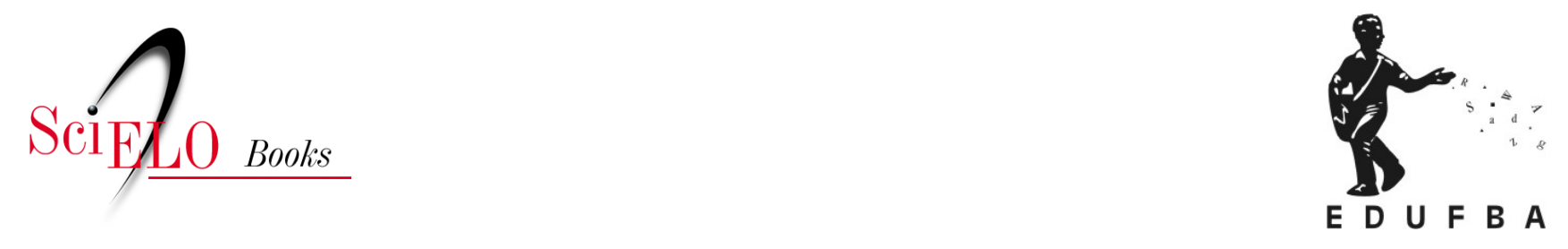

\title{
O auxílio-acidente e o Regime Geral da Previdência Social
}

\author{
Carlos Eduardo Soares de Freitas
}

\section{SciELO Books / SciELO Livros / SciELO Libros}

FREITAS, C.E.S. O auxílio-acidente e o Regime Geral da Previdência Social. In: Auxílio-acidente e saúde do trabalhador [online]. Salvador: EDUFBA, 2018, pp. 69-99. ISBN: 978-85-232-1875-1. https://doi.org/10.7476/9788523218751.0004

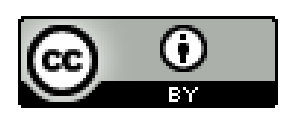

All the contents of this work, except where otherwise noted, is licensed under a Creative Commons Attribution $\underline{4.0 \text { International license. }}$

Todo o conteúdo deste trabalho, exceto quando houver ressalva, é publicado sob a licença $\underline{\text { Creative Commons }}$ Atribição 4.0. 


\section{O auxílio-acidente e o Regime Geral da Previdência Social}

Este capítulo propõe-se, inicialmente, a refletir sobre as condições para a concessão do benefício do auxílio-acidente, assim como a sua natureza jurídica indenizatória e a posição em relação a outros benefícios do Regime Geral da Previdência Social no tocante à incapacidade laboral. Objetiva ainda analisar o benefício como política de prevenção a acidentes de trabalho e, nesse campo jurídico-político, examina tanto a responsabilidade do Estado, quanto a postura administrativa que tem sido adotada para reaver custos provocados por doenças e acidentes do trabalho.

\section{A concessão do auxílio-acidente}

A concessão do auxílio-acidente segue uma dinâmica própria: após a ocorrência do evento (acidente ou doença, do trabalho ou não) que provoca o afastamento compulsório e temporário do trabalhador (empregado, avulso ou segurado especial) da atividade laboral por no mínimo i6 dias, devidamente atestado por profissional médico, deverá ser o segurado encaminhado ao INSS, que implantará 
o auxílio-doença; o segurado então será submetido à perícia, para fins de conhecimento, pelo órgão, de apuração do estado geral de saúde do segurado e das perspectivas para o retorno ao trabalho. Na hipótese posterior de alta, o auxílio-doença cessará e a perícia verificará se restaram sequelas consolidadas decorrentes do evento e que venham a provocar redução na capacidade produtiva do segurado em relação à função que exercia na época em que fora afastado. ${ }^{1}$ Constatando-se a hipótese, o INSS liberará o trabalhador ao labor com restrições e implantará o auxílio-acidente. Antes da alta, o órgão previdenciário poderá encaminhá-lo ao serviço de reabilitação profissional para permitir-lhe a oportunidade de ocupar outras funções laborais.

As outras hipóteses são:

I. em caso do segurado recuperar plenamente a capacidade laborativa, ele retornará ao trabalho após a alta sem a necessidade de qualquer benefício;

2. se houver piora no estado geral de saúde do segurado e constatada, pela perícia, a incapacidade total e permanente para o trabalho, o INSS transformará o auxílio-doença em aposentadoria por invalidez;

3. se o segurado que se encontrar afastado temporariamente ao INSS falecer, o órgão concederá pensão por morte nas hipóteses previstas em Lei e se houver dependente.

A hipótese de concessão do auxílio-acidente, no entanto, poderá sofrer percalços. Ao dispor sobre a viabilidade do benefício para acidentes não relacionados ao trabalho, a concessão esbarra em um empecilho: trata-se da hipótese de auxílio-doença que deixou de ser concedido por falta de carência (número mínimo de recolhimentos previdenciários imediatamente anteriores ao evento que

1 Note o leitor que a tendência jurisprudencial pesquisada no capítulo 1 aponta também a necessidade de auxílio-doença para afastar o segurado das condições de trabalho que o deixaram sequelado. 
provocou o afastamento, que é de I2 meses, no caso), fator que não é exigível em acidentes ou doenças do trabalho. Com isso, chega-se a uma dificuldade para o segurado, que sem a carência tem o seu contrato de trabalho suspenso, mas não acolhido pelo INSS, e ao ter condições de retornar ao trabalho, o mesmo INSS deverá apurar se as lesões deixaram sequelas que limitam a produtividade laboral na função que exercia quando do afastamento. Nesse caso, se concederia o auxílio-acidente mesmo em acidentes de qualquer natureza, conforme expressa o art. 26, I, da Lei no 8.213/9I e o art. 30, I, do Decreto no 3.048/99.

Prevê-se, no entanto, uma exceção, que é a ocorrência de doenças especificadas em lista do Ministério da Saúde. Nesses casos, mesmo que não sejam relacionadas ao trabalho, não se exige a carência. É o que prevê o art. 30 do Decreto nº 3.048/99:

III - auxílio-doença e aposentadoria por invalidez nos casos de acidente de qualquer natureza ou causa, bem como nos casos de segurado que, após filiar-se ao Regime Geral de Previdência Social, for acometido de alguma das doenças ou afecções especificadas em lista elaborada pelos Ministérios da Saúde e da Previdência e Assistência Social a cada três anos, de acordo com os critérios de estigma, deformação, mutilação, deficiência ou outro fator que the confira especificidade e gravidade que mereçam tratamento particularizado; (BRASIL, I999)

No caso acima, supõe-se menor dificuldade de acesso ao auxílio-acidente, pois o segurado estaria afastado ao INSS e submetido às perícias do órgão previdenciário.

Concedido o auxílio-acidente, o segurado não necessitaria submeter-se a perícias do INSS para averiguação dos efeitos das sequelas, isto é, se estas continuariam a provocar redução da capacidade produtiva na função exercida anterior ao evento. Diferente, neste caso, da aposentadoria por invalidez, dada a realização de eventuais perícias pelo aposentado. 
Outra dificuldade para o segurado se dá quando este se encontra desempregado. Aí, o direito ao auxílio-acidente será preservado enquanto mantiver sua condição de segurado:

A legislação proibia a concessão de auxílio acidente, quando o segurado estivesse desempregado, durante o período de manutenção da qualidade de segurado. O Decreto 6.733 de 30/12/08, todavia, alterou a redação do art. $7^{\circ}$, do art. I04, do RPS, permitindo a concessão do auxílio acidente durante o período de graça. (KERTZMAN, 20I2, p. 439)

Isto é, se o fato gerador do benefício ocorreu ainda no período de graça, o segurado terá garantido o direito ao benefício.

o auxílio-acidente, como benefício previsto ao segurado que sofreu os efeitos de acidente ou doença e que passou a ter capacidade produtiva reduzida, diferencia-se de modo peculiar dos demais benefícios. As aposentadorias, por exemplo, servem nitidamente para proporcionar ao segurado a possibilidade de não mais trabalhar; o auxílio-doença e a licença-maternidade se pautam na incapacidade laboral temporária, mesmo que por motivos distintos; já o auxílio-reclusão e a pensão por morte ocupam-se em auxiliar no sustento dos dependentes. Todos se referem a situações em que segurados ou dependentes devem prover o futuro com alimentos, assim, os benefícios funcionam como proventos propriamente ditos, a substituir os ganhos normais do trabalhador apto ao labor.

O auxílio-acidente não tem esses traços: ele comparece como uma compensação por perda decorrente de fato anterior (acidente ou doença). Poderia ter proximidade com a aposentadoria por invalidez, mas por esta exigir a impossibilidade do labor, se distancia do auxílio-acidente, pago simultaneamente ao ganho oriundo do trabalho, como o salário do empregado. São características do auxílio-acidente que o alinham de forma indiscutível ao formato de indenização, enquanto os demais mantêm função alimentar. Afinal, o auxílio-acidente diz respeito a algo que ocorreu no passa- 
do e que provocou efeito deletério na saúde do segurado, de modo a marcá-lo em definitivo em sua capacidade de produzir, afetando-o por consequência no alcance de remunerações compatíveis com uma produtividade integral.

Para além da interpretação literal e acompanhando a jurisprudência, é razoável considerar a extensão do benefício partindo-se do impacto dos efeitos do acidente, ou doença, para a sua vida em geral, em dimensão maior que para a sua vida produtiva. Por todo o acúmulo de nossa civilização sobre o universo complexo da previdência e, desde 1988, com seu vínculo com a seguridade, é sensato e racional refletir sobre as consequências do infortúnio para além da capacidade produtiva exclusivamente. Esse é um debate que vem se dando na sociedade de maneira insistente e silenciosa, a permitir que a seguridade social "saia do papel" e encontre a realidade. $^{2}$

Nessa mesma passada, esclareça-se que o dano justificador do auxílio-acidente não necessita atingir determinado e elevado patamar para que torne o benefício acessível. O STJ posicionou-se de forma explícita nesse sentido:

Previdenciário. Recurso especial representativo da controvérsia. Auxílio acidente. Lesão mínima. Direito ao benefício. I. Conforme o disposto no art. 86, caput, da Lei 8.213/9I, exige-se, para concessão do auxílio acidente, a existência de lesão, decorrente de acidente do trabalho, que implique redução da capacidade para o labor habitualmente exercido. 2. O nível do dano e, em consequência, o grau do maior esforço, não interferem na concessão do benefício, o qual será devido ainda que mínima a lesão. 3. Recurso especial provido. [REsp I.I09.59I-SC (2008/0282429-9). Relator Ministro

2 Sobre a dificuldade de implantação da política previdenciária no país e, mais ainda, da seguridade social nos termos da Constituição de 1988, conferir a análise pessimista e de certa forma atual, de Gomes e Gottschalk (1994). 
Celso Limongi (Desemb. Conv. do TJ/SP), Sexta Turma; julgado em 25/O8/20IO]. (BRASIL, 2OIOb)

E, posteriormente, a TNU:

Auxílio-acidente. Dano mínimo. Possibilidade. Entendimento consolidado na TNU. PEDILEF 5002773-47.2012.4.04.7118. ${ }^{3}$

Nessa linha, o auxílio-acidente se identifica como indenização que busca compensar um dano material, ou "o prejuízo financeiro efetivo sofrido pela vítima, causando por conseqüência uma diminuição do seu patrimônio, avaliável monetariamente" (OLIVEIRA, 2007, p. 200), o que não exclui seu enquadre também como dano moral, uma vez que a redução da capacidade produtiva tende a implicar em efeitos negativos para a saúde, bem extrapatrimonial tutelado pela Constituição. Com a riqueza jurídica trazida pelo Direito Constitucional ao direito a uma vida digna e, nessa esteira, pela contribuição teórica significativa dos direitos da personalidade inscritos no Código Civil de 2002, a ofensa à saúde, enquanto bem tutelado, se impõe na atualidade também como uma ofensa à moral.

As numerosas ações trabalhistas que buscam indenizações por danos morais decorrentes de prejuízos ocupacionais à saúde obreira pautam-se nesse mesmo debate. A questão suscita, assim, a possibilidade de se encarar o auxílio-acidente não apenas como dano material, conforme registrado em parte da literatura, mas também como dano moral sofrido pelo segurado. Um assunto que não necessariamente provocaria discussões legislativas em torno da majoração do valor do benefício, mas que por certo deve ser aprofundada, pela riqueza jurídica que proporciona e para, em termos práticos, subs-

3 Decisão da Tuma Nacional de Uniformização que já não consta da página eletrônica do Portal da Justiça Federal. 
tanciar ainda mais a responsabilidade patronal pelo dano em ações judiciais de iniciativa do INSS.

Quadro 2 - Destinos possíveis do segurado beneficiário do Auxílio-doença acidentário

\begin{tabular}{|l|l|l|}
\hline Situação hipotética & Após a perícia do INSS... & Consequências \\
\hline $\begin{array}{l}\text { 1. O segurado se recuperou } \\
\text { integralmente }\end{array}$ & O segurado obtém alta do INSS & $\begin{array}{l}\text { O segurado volta ao trabalho, } \\
\text { sem restrições e com garantia } \\
\text { no emprego por 12 meses }\end{array}$ \\
\hline $\begin{array}{l}\text { 2. O segurado permaneceu } \\
\text { temporariamente incapacitado }\end{array}$ & $\begin{array}{l}\text { O segurado continua a receber } \\
\text { auxílio-doença }\end{array}$ & $\begin{array}{l}\text { O segurado permanece } \\
\text { afastado junto ao INSS }\end{array}$ \\
\hline $\begin{array}{l}\text { 3. O segurado se recuperou, } \\
\text { mas com sequela parcialmente } \\
\text { incapacitante }\end{array}$ & $\begin{array}{l}\text { O segurado obtém alta do } \\
\text { INSS, com concessão de } \\
\text { auxílio-acidente a partir do } \\
\text { encerramento do auxílio-doença }\end{array}$ & $\begin{array}{l}\text { O segurado volta ao trabalho, } \\
\text { com restrições e com garantia } \\
\text { no emprego por 12 meses }\end{array}$ \\
\hline $\begin{array}{l}\text { 4. O segurado não se } \\
\text { recuperou e foi diagnosticado } \\
\text { inválido }\end{array}$ & $\begin{array}{l}\text { O segurado tem seu } \\
\text { benefício transformado em } \\
\text { aposentadoria por invalidez }\end{array}$ & $\begin{array}{l}\text { O segurado não poderá } \\
\text { voltar a trabalhar e a rescisão } \\
\text { contratual será confirmada }\end{array}$ \\
\hline 5. O segurado vem a falecer 5 anos
\end{tabular}

Fonte: Elaborado pelo autor.

\section{O auxílio-acidente como benefício do Regime Geral de Previdência Social}

O auxílio-acidente é um benefício exclusivo do regime geral da previdência social, não se verificando similar em regimes próprios de servidores públicos. Para o servidor incapacitado não totalmente para o trabalho, resta-lhe a alta, com o retorno para as atividades laborais ou, se for o caso, a concessão da aposentadoria por invalidez, em caso de plena incapacidade, seja decorrente do trabalho ou não. 
Como método de comparação com o RGPS, tem-se as legislações de dois diferentes regimes: o dos servidores públicos do Estado da Bahia e o dos servidores públicos civis federais.

Recente alteração na Lei previdenciária dos servidores públicos estaduais da Bahia atenta para uma questão que envolve o debate sobre o auxílio-acidente. É que ao dispor sobre a concessão da aposentadoria por invalidez, a Lei estadual no II.357/2009, ao contrário da anterior (Lei no 6.677/94), toma como referência a incapacidade em relação ao cargo e não em relação à função.

Em se tratando de servidor público, cujo ingresso na administração se dá por concurso para um determinado cargo, há coerência na medida. E como não há previsão legal para mudanças de cargos, pelo servidor, desacompanhado de concurso, a incapacidade para o cargo ao qual fora nomeado não justificaria a alteração para outro cargo (para o qual não fora aprovado em concurso público), mas a sua aposentadoria. Trata-se de rigor adequado ao serviço público e compatível com os limites constitucionais, mesmo na hipótese (não legal), do ponto de vista da capacidade laboral do servidor, que este venha a ocupar cargo diverso em razão das sequelas que comprometam parcialmente a sua produção para o cargo ao qual fora nomeado.

Há aí um paradoxo ao tomar-se como parâmetro a regra do RGPS, pois para o servidor, a aposentadoria por invalidez poderia se justificar na incapacidade parcial e permanente, e não na incapacidade total e permanente. Dito dessa forma, é razoável a dúvida quanto à justeza ou não da concessão da aposentadoria por invalidez que não reflita a invalidez plena do trabalhador.

Outra dúvida possível se encaixa em situação prevista pela Lei previdenciária de 1976 e esquecida por sua sucessora: o que fazer em relação ao servidor que, ao retornar ao serviço após afastamento temporário e compulsório, tem a sua capacidade laboral parcialmente recuperada, mas se vê obrigado a um maior esforço e às 
vezes excessivo? São temas não completamente resolvidos e que aguardam o devido amadurecimento por parte da sociedade, até pelos efeitos provocados por novas formas de exploração do trabalho, caracterizadas pela agudização das condições precárias (DRUCK; FRANCO, 2007) e pela busca insana por metas, que geram mais e mais agravos físicos e mentais aos trabalhadores, sejam eles celetistas ou servidores.

A Lei no 8.II2/9o, que regula o Regime Jurídico Único (RJU) dos servidores públicos civis da União, não trata de um benefício específico para a situação do servidor vítima de evento que lhe provoque incapacidade parcial e permanente. Diz o trecho específico da Lei:

Art. I85. Os benefícios do Plano de Seguridade Social do servidor compreendem:

I - quanto ao servidor:

a) aposentadoria;

b) auxílio-natalidade;

c) salário-família;

d) licença para tratamento de saúde;

e) licença à gestante, à adotante e licença-paternidade;

f) licença por acidente em serviço;

g) assistência à saúde;

h) garantia de condições individuais e ambientais de trabalho satisfatórias;

(BRASIL, I99Ia)

Os benefícios caracterizam-se pela natureza alimentar, como substitutivos do vencimento do servidor. Não há uma indenização como o auxílio-acidente do RGPS. 
Os exemplos analisados anteriormente ilustram a falta injustificada de um benefício indenizatório na regulamentação dos regimes próprios dos servidores públicos. Mas mesmo sem as regras do RGPS, situações fáticas pelas quais passam os servidores devem ser avaliadas juridicamente a partir do direito à saúde e ao bem-estar. Uma hipótese seria a do servidor sequelado que, para exercer as atividades do seu cargo, passa a se esforçar mais do que fazia no passado, quando era plenamente saudável; esse esforço não pode ser insuportável e o trabalhador deve permanecer no limite do saudável, sob pena de agravamento do prejuízo ou geração de outro dano. Mais uma situação que aguarda solução.

Quanto aos servidores públicos do Estado da Bahia, há outro fato a ser analisado. Os policiais militares, após exerceram, mesmo sem a permissão constitucional, o direito de greve nos anos de $200 \mathrm{I}$ e de 20I2, passaram a gozar do direito a uma indenização denominada auxílio-acidente, conforme a Lei no 7.990, de 27 de dezembro de $200 \mathrm{I}$ - que "dispõe sobre o Estatuto dos Policiais Militares do Estado da Bahia e dá outras providências" -. A vantagem foi aprovada após a movimentação coletiva que a categoria profissional realizou em 200I, mas a Lei tratou da indenização sem definir as condições para concedê-la. Anomia parcial que ainda persiste e que foi lembrada pelos policiais manifestantes em 20I2, mas sem resultados. Dispõe a Lei de 200I, que ainda segue sem regulamento:

Art. IO2 - A remuneração dos policiais militares é devida em bases estabelecidas em legislação peculiar, compreendendo:

$[\ldots]$

$\S 2^{0}$ - São indenizações devidas ao policial militar no serviço ativo:

$[\ldots]$

Auxílio-acidente;

(BAHIA, 2OOI) 
Nesse caso, não há qualquer indicação na Lei se a indenização se refere à hipótese de incapacidade parcial e permanente, como historicamente se constituiu o auxílio-acidente e conforme se justifica no regime geral da previdência social. Mesmo sem a regulamentação, o que torna a Lei inócua, parece relevante aos servidores públicos, não só militares, que a proposta de uma indenização denominada auxílio-acidente seja possível de constar em norma.

A interpretação sobre benefícios previdenciários em regimes próprios pode se apoiar na analogia às normas do RGPS, na falta de regras específicas nesses regimes e respeitados os princípios e limites da razoabilidade e da proporcionalidade. Um caso chamou a atenção da sociedade quando tratado pelo STF: a aplicação da regra do RGPS para a concessão de aposentadoria especial ao servidor público federal.

\section{A responsabilidade do Estado e o auxílio-acidente}

O custeio dos benefícios relacionados ao acidente de trabalho e das aposentadorias especiais tem como base o recolhimento do Seguro contra Acidentes de Trabalho, conhecido como SAT. A fonte é exclusivamente da empresa, não havendo a correspondente parte do trabalhador, como ocorre no recolhimento previdenciário regular que custeia os benefícios comuns. Duas formas de contribuições são previstas: a RAT, Riscos Ambientais do Trabalho, sobre a folha integral mensal, dividida em graus distintos de riscos (I\%, quando considerado leve; $2 \%$, médio e $3 \%$, grave); e outra, a título de acréscimo, quando há ambientes compatíveis com a concessão da aposentadoria especial e que recai sobre "a remuneração do segurado sujeito às condições especiais que prejudiquem a saúde ou a integridade física". (EDUARDO, I.; EDUARDO, J.; TEIXEIRA, 2002, p. 47)

Tratamento similar é observado aos cooperativados de cooperativas de trabalho em relação às contribuições dirigidas ao fi- 
nanciamento de aposentadorias especiais, conforme dispõe a Lei $\mathrm{n}^{0}$ Io.666/2003. Para os segurados especiais, a cobertura dos acidentes de trabalho está incluída em o,r\% dentro da alíquota de $2,3 \%$, incidente sobre o valor bruto da comercialização da produção rural. Outra fonte é prevista no art. 62 da Lei no 8.2I2/9I:

Art. 62. A contribuição estabelecida na Lei nº 5.I6I, de 2I de outubro de 1966, em favor da Fundação Jorge Duprat Figueiredo de Segurança e Medicina do Trabalho - FUNDACENTRO, será de $2 \%$ (dois por cento) da receita proveniente da contribuição a cargo da empresa, a título de financiamento da complementação das prestações por acidente do trabalho, estabelecida no inciso II do art. 22.

Parágrafo único. Os recursos referidos neste artigo poderão contribuir para o financiamento das despesas com pessoal e administração geral da Fundação Jorge Duprat Figueiredo de Segurança e Medicina do Trabalho - Fundacentro. (BRASIL, I99Ib)

Como medida de estímulo à prevenção, o Decreto nº 6.042/2007 alterou o Decreto no 3.048/99, para instituir o Fator Acidentário de Prevenção, o FAP, como meio de reduzir ou aumentar as aquelas alíquotas de $\mathrm{I}^{\mathrm{O}}, 2^{\mathrm{O}}$ ou $3^{\circ}$, previstas para o financiamento do RAT. O FAP compara o grau de risco da empresa com o risco da atividade econômica (mensurado a partir do CNAE) e se houver variação para menos, isto é, menor o risco, se reduz a contribuição; caso a variação seja maior, aumenta-se a contribuição. Essa é a conclusão de Santos (20II, p. 67): "Objetiva-se que seja maior o valor da contribuição das empresas em que com mais freqüência ocorram acidentes, e, ainda, aquelas em que os acidentes sejam menos freqüentes ou menos graves contribuirão com alíquota menor".

Ser o único benefício do RGPS com natureza indenizatória faz com que sobre o auxílio-acidente se permita à discussão sobre a responsabilidade do Estado para além do custeio articulado para o seu financiamento. Afinal, a indenização é um instituto dos mais 
polêmicos no Direito, assim como a responsabilidade, e ambos possuem, entre si, um elo indiscutível, pois ao levantar a possibilidade de um indivíduo indenizar outro, conclui-se pela responsabilidade daquele que deve indenizar.

De uma forma geral, a Constituição responsabiliza objetivamente o Estado por danos causados a terceiros. (BRASIL, I988, Art. 37, §6) A previdência social pública comporta o papel de seguradora de trabalhadores e empresas que a ela contribuem e os acidentes de trabalho fazem parte do escopo dessa política. A finalidade da previdência social, segundo a Constituição Federal, volta-se à cobertura de eventos como morte, invalidez, doença e idade avançada; à proteção, à maternidade e aos efeitos do desemprego compulsório; e à sustentação de dependentes de segurados de baixa renda, por meio do salário-família e do auxílio-reclusão. (BRASIL, I988, Art. 20I, incisos I, II, III) Quanto ao acidente de trabalho, a Emenda Constitucional $\mathrm{n}^{\mathrm{0}}$ 20/98 alterou o texto constitucional para assim dispor: "Art. $20 \mathrm{I}$. [...] § Io. Lei disciplinará a cobertura do risco de acidente do trabalho, a ser atendida concorrentemente pelo regime geral de previdência social e pelo setor privado". (BRASIL, I988)

$\mathrm{O}$ acidente de trabalho, como tema que faz parte do ambiente de trabalho, deve ser compreendido de modo amplo, com a articulação de outros dispositivos constitucionais: o artigo 200, que trata das competências do Sistema Único de Saúde (SUS) e inclui a execução de "ações de vigilância sanitária e epidemiológica, bem como as de saúde do trabalhador"; o art. 225, que garante a todos o direito ao meio ambiente ecologicamente equilibrado e impõe ao Poder Público o dever de preservá-lo; e o art. $7^{\circ}$, que enquadra como direitos dos trabalhadores a "redução dos riscos inerentes ao trabalho, por meio de normas de saúde, higiene e segurança" e a "proteção em face da automação, na forma da Lei". (BRASIL, I988, incisos XXII, XXVII) Quando cuida dos trabalhadores que são servidores públicos, o art. 40 da Constituição garante a cobertura dos 
regimes próprios também para os efeitos do que chama "acidente em serviço" e "moléstia profissional", correspondentes ao acidente e à doença do trabalho nas relações de trabalho cobertas pelo RGPS. (BRASIL, I988)

As condições para a concessão do auxílio-acidente, no âmbito do regime geral, devem ser apuradas pela previdência pública, por meio da perícia do INSS. Constatada a incapacidade parcial e permanente com efeito negativo na capacidade produtiva do segurado, deve ser implantado o benefício. Portanto, constitui obrigação exclusiva do órgão previdenciário do Estado, o INSS: realizar a perícia e, a depender do apurado, conceder, implantar e pagar o auxílio-acidente. A responsabilidade do INSS em conceder e pagar o benefício ao segurado, no entanto, poderá ser transferida à empresa (empregadora) que permitiu, por negligência, que o acidente ou doença do trabalho ocorresse e provocasse danos ao segurado. É de responsabilidade da empresa manter o ambiente de trabalho saudável, é o que prevê o art. I2O da Lei 8.213/9I: "Nos casos de negligência quanto às normas padrão de segurança e higiene do trabalho indicados para a proteção individual e coletiva, a Previdência Social proporá ação regressiva contra os responsáveis". (BRASIL, I99Ib)

O argumento não deve se limitar à obrigação da empresa conforme o dispositivo acima, mas, antes mesmo disso, observar que a Constituição Federal de 1988 estabeleceu um novo marco civilizatório e republicano, por meio da imposição da função social da propriedade, como afirma Jorge Luiz Souto Maior (20I2):

Não se pode esquecer, ademais, que o Estado atual é o Estado de Direito Social e neste sentido rege-se, juridicamente, pela obrigação de garantir a eficácia dos direitos sociais, constitucionalmente consagrados, não lhe cabendo, portanto, assegurar o direito de propriedade numa perspectiva meramente liberal, até porque também esse direito está vinculado a cum- 
prir uma função social e isso não é retórica, tratando-se de expressão inequívoca da Lei.

A responsabilidade do Estado seria fundada na teoria do risco social, aprofundada na Constituição, "partindo do pressuposto de que a empresa, reunindo os fatores de produção, por mais nocivos que sejam ao trabalhador, presta essencial colaboração a toda a sociedade". (DINIZ, 2003, p. 156) Zéu Palmeira Sobrinho (2012, p. 7I) aprofunda esse enfoque sem desprezar a responsabilidade do empregador:

No plano específico do direito previdenciário, a proteção ao acidentado é baseada da teoria do risco social, também chamada de seguro social. O cerne dessa teoria funda-se na constatação de que as atividades laborativas são exploradas com o objetivo de prover a demanda da sociedade por bens e serviços. Portanto, a sociedade - por ser destinatária dos frutos do trabalho - é quem detém a legitimidade para assumir o encargo de reparar o trabalhador acidentado. A assunção de tal obrigação pela sociedade se dá por meio do Estado, posto que somente este tem sido considerado apto para tratar a proteção social de forma desmercantilizada, possibilitando a universalidade da cobertura e do atendimento.

\section{$[\ldots]$}

A teoria do risco social representa, portanto, uma alternativa à insuficiência da repartição coletiva dos riscos. Na típica socialização dos riscos não se perquire sobre a existência de culpa. O direito previdenciário brasileiro, sob esse aspecto, ampara a socialização absoluta dos riscos acidentários por parte do empregado, mas não isenta o patrão se este concorre culposamente para a ocorrência do acidente do trabalho. Sob esse aspecto, o art. I2O da Lei n. 8.213/1991, estabelece que nos casos de negligência quanto às normas padrão de segurança e higiene do trabalho indicados para a proteção individual e coletiva, a Previdência Social proporá ação regressiva contra os responsáveis. Enfim, a teoria do risco social encartada pelo 
direito acidentário sinaliza para o declínio da responsabilidade individual do patrão, sem abandoná-la totalmente.

A teoria do risco social não caminha em descompasso com a função social da propriedade. É necessário demarcar que não cabe às empresas que empregam trabalhadores gerar doenças ou acidentes de trabalho. Ao contrário: é obrigação delas proporcionar um ambiente de trabalho saudável e ecologicamente equilibrado. Há suficiente regulamentação para tratar do assunto, de maneira que não se pode alegar anomia ao tratar de um Direito Ambiental do Trabalho.

Se a empresa, enquanto propriedade, deve zelar por sua função social, conclui-se ser antijurídico que ela ameace a saúde das pessoas, sejam elas trabalhadores (proteção à saúde do trabalhador), consumidores (proteção à saúde do consumidor - artigo 6º I, CDC) ou cidadãos em geral (artigo 225 da CF). Pode haver, entre especialistas, divergências quanto à aplicação da teoria da responsabilidade objetiva ou subjetiva, embora o Código de Defesa do Consumidor (Lei $n^{\circ}$ 8.078/90) responsabilize, independente de culpa, o fabricante, o produtor, o construtor e o importador, por danos causados ao consumidor. A aplicação da responsabilidade objetiva na área consumerista é plenamente compatível com uma norma anterior, a Lei no 6.938/8I, que cuida da nossa Lei ambiental, ao dispor sobre as obrigações do "poluidor":

Art. $3^{\circ}$ - Para os fins previstos nesta Lei, entende-se por:

$[\ldots]$

IV - poluidor, a pessoa física ou jurídica, de direito público ou privado, responsável, direta ou indiretamente, por atividade causadora de degradação ambiental;

$[\ldots]$ 
Art. $4^{0}$ - A Política Nacional do Meio Ambiente visará:

$[\ldots]$

VII - à imposição, ao poluidor e ao predador, da obrigação de recuperar e/ou indenizar os danos causados e, ao usuário, da contribuição pela utilização de recursos ambientais com fins econômicos.

$[\ldots]$

Art. I4 - Sem prejuízo das penalidades definidas pela legislação federal, estadual e municipal, o não cumprimento das medidas necessárias à preservação ou correção dos inconvenientes e danos causados pela degradação da qualidade ambiental sujeitará os transgressores:

$[\ldots]$

$\S \mathrm{I}^{\mathrm{O}}$ - Sem obstar a aplicação das penalidades previstas neste artigo, é o poluidor obrigado, independentemente da existência de culpa, a indenizar ou reparar os danos causados ao meio ambiente e a terceiros, afetados por sua atividade. O Ministério Público da União e dos Estados terá legitimidade para propor ação de responsabilidade civil e criminal, por danos causados ao meio ambiente. (BRASIL, I98I)

A articulação dessas diferentes normas é possível e jurídica em vista da necessidade da proteção à saúde, bem constitucionalmente tutelado, especialmente pela empresa (ou propriedade), que deve manter sua função social, isto é, a contribuição para que o Estado de Direito Social (conforme interpreta Souto Maior) se confirme enquanto balizador civilizatório e republicano (LEWANDOWSKI, 2005), em nossa sociedade. Mas se nos campos do consumidor e da proteção ao ambiente a responsabilidade objetiva do fabricante ou produtor/poluidor é indiscutível, como não admitir essa mesma teoria objetiva nas relações de trabalho?

A dificuldade em admitir a aplicação de tal teoria residiria em interpretação de dispositivo constitucional específico - "Artigo $7^{\circ}$. 
[...] XXVIII - seguro contra acidentes de trabalho, a cargo do empregador, sem excluir a indenização a que este está obrigado, quando incorrer em dolo ou culpa" - (BRASIL, I988), que não dispensaria a culpa. No entanto, é possível e compatível com o texto constitucional a interpretação que resulte na aplicação da responsabilidade objetiva do empregador em eventos de acidentes ou doenças do trabalho. Para tanto, pode-se argumentar não apenas a defesa daquela norma ambiental, que é bastante clara em sua intenção, mas também regra recente introduzida pelo novo Código Civil (Lei nº I0.406/2002), cujo parágrafo único de artigo 927 dispõe:

Art. 927. Aquele que, por ato ilícito (arts. I86 e i87), causar dano a outrem, fica obrigado a repará-lo.

Parágrafo único. Haverá obrigação de reparar o dano, independentemente de culpa, nos casos especificados em Lei, ou quando a atividade normalmente desenvolvida pelo autor do dano implicar, por sua natureza, risco para os direitos de outrem. (BRASIL, 20O2)

Os riscos ambientais do trabalho são regulados no Brasil há muitos anos por meio das Normas Regulamentadoras, ou NRs, aprovadas a partir da Portaria no 3.2I4/78. As NRs dispõem, em geral, sobre obrigações patronais para assegurar condições adequadas e ecologicamente equilibradas e saudáveis. São essas as normas, independente de outras, as quais fazem referência o inciso XXII do artigo $7^{\circ}$ da Constituição - "redução dos riscos inerentes ao trabalho, por meio de normas de saúde, higiene e segurança" -.

Aspecto relevante que não pode ser esquecido, é que equiparadas às doenças relacionadas ao trabalho, estão aquelas provocadas também pelo trabalho, isto é, o fator laboral esteve presente, mas não foi o único responsável a gerar a doença. Nessa situação, configura-se a concausa, aceita pacificamente nos tribunais brasileiros.

Assim, com a adoção da teoria da responsabilidade subjetiva, a hipótese de descumprimento de uma Norma Reguladora (NR) im- 
plicaria em negligência da empresa. Mas considerando-se que as NRs buscam exatamente ajustar ambientes e condições de trabalho para a eliminação ou redução de riscos, é razoável compreender que as normas encaram as relações de trabalho, em geral, como aquelas em que os riscos à saúde lhe são inerentes (exatamente como menciona o texto constitucional acima transcrito) e sempre presentes. Nesse caso, há de se reconhecer a teoria objetiva com o intuito de responsabilizar o empregador, com apoio tanto naquela legislação ambiental quanto no artigo 927, § único, do Código Civil. Aproximam-se a teoria objetiva da teoria do risco profissional.

O debate sobre a aplicação da teoria objetiva nas relações de trabalho para obrigar o empregador a assumir e reparar danos vinculados a acidentes ou doenças do trabalho encontra importante e crescente espaço em nosso país. Contribuem para o debate, não necessariamente na defesa da teoria objetiva, autores como Sebastião Geraldo de Oliveira (2007), Raimundo Simão de Melo (20IO), Cláudio Brandão (2006), Dallegrave Neto (20I0), Julio de Sá Rocha (2002), Ana Paola Santos Machado Diniz (2003), José Antônio Ribeiro de Oliveira Silva (2008), Zéu Palmeira Sobrinho (20I2) e Márcia Picarelli (2005).

Desenha-se como um debate rico e fundamental, mas para o INSS acionar judicialmente as empresas em ações regressivas, não há necessidade do debate teórico sobre a responsabilidade objetiva ou subjetiva. O artigo I2O da Lei no 8.213/9I exige a comprovação da negligência da empresa como condição para a ação. Ao falar em "proporá", a Lei obriga o INSS a acionar as empresas. Se considerarmos que essa obrigação do poder público é normatizada desde I99I, é possível concluir que o INSS tem sido tímido no ajuizamento desse tipo de ação, de alcance relevante na política de prevenção a acidentes e na defesa da saúde do trabalhador, que visa condenar as empresas nos custos dos eventos gerados por sua negligência. No caso do auxílio-acidente, a ação regressiva justifica-se apenas 
quando se tratar de acidente ou doença do trabalho. A mesma regra se aplica aos demais benefícios acidentários.

A respeito do tema, Schwarz comenta (2012, p. I89):

Quanto aos benefícios decorrentes de acidente do trabalho, nos casos de negligência quanto às normas padrão de segurança e higiene do trabalho indicados para a proteção individual e coletiva, a Previdência Social proporá ação regressiva contra os responsáveis (art. I2O da Lei n. 8.213/199I). O pagamento, pela Previdência Social, das prestações por acidente do trabalho (auxílio acidente, auxílio-doença ou aposentadoria por invalidez) não exclui a responsabilidade civil da empresa ou de outrem.

Para ilustrar a discussão, seguem exemplos de julgados dos Tribunais Regionais do país que marcam a negligência patronal no que toca essa singular ação judicial. Os julgados coletados da I $^{\mathrm{a}}$ Região alertam para a prática negligente da empresa no tocante ao desrespeito aos dispositivos das Normas Regulamentadoras:

Processual civil e civil. Responsabilidade civil. Acidente de trabalho Negligência do empregador. Ação regressiva. I. "Nos casos de negligência quanto às normas padrão de segurança e higiene do trabalho indicados para a proteção individual e coletiva, a Previdência Social proporá ação regressiva contra os responsáveis» (Lei no 8.213/9I, art.I20). 2. O INSS logrou êxito em comprovar as alegações contidas na inicial de que o acidente decorreu de negligência da empresa empregadora quanto às normas de segurança do trabalho indicadas para a proteção de seus trabalhadores, por meio de autos de vistoria lavrados pela Delegacia do Trabalho, devendo a empresa ré, nessas circunstâncias, indenizar regressivamente a Previdência Social pelos valores despendidos com o pagamento de benefícios previdenciários aos dependentes do falecido. 3 . Nega-se provimento ao recurso de apelação. [Apelação Cível I999.38.00.02I282-2/MG; Juiz Federal Rodrigo Navarro de Oli- 
veira, $5^{\text {a }}$ Turma Suplementar; julgado em 03/04/2012]. (BRASIL, 20I2f)

Responsabilidade civil. Acidente em serviço. Pensão por morte. Ação de regresso pelo INSS. I. Consoante o art. I2O da Lei n. 8.213/1991, "nos casos de negligência quanto às normas padrão de segurança e higiene do trabalho indicados para a proteção individual e coletiva, a Previdência Social proporá ação regressiva contra os responsáveis». 2. Tal como o perito do Ministério do Trabalho e Emprego, a perícia judicial apontou como causa do acidente que vitimou fatalmente o empregado da ré - atingido por laje que desabara durante o serviço de retirada das escoras de sustentação - o fato de que "a empresa não vinha adotando as medidas de segurança exigidas pelas normas regulamentares, em especial as NRs 04 , 05 e I8 da Portaria Ministerial 3.2I4 de 08/06/1978", dando suporte ao reconhecimento do direito de regresso do INSS em relação ao ressarcimento dos gastos com a pensão conferida à viúva. 3. Apelação a que se nega provimento. [Apelação Cível 2002.32.00.0046249/AM; Relator Desembargador Federal João Batista Moreira; $5^{\text {a }}$ Turma; julgado em I8/OI/20I2] (BRASIL, 2OI2a)

Previdenciário e civil. Responsabilidade civil. Acidente de trabalho. Ação regressiva ajuizada pelo INSS contra o empregador. I. É constitucional a previsão de ressarcimento do INSS a que se refere o art. I2O da Lei no 8.213/9I. 2. O INSS é parte legítima para ajuizar ação contra o empregador que não observou as normas de segurança do trabalho, a fim de reaver as despesas decorrentes da concessão de benefício previdenciário aos filhos de empregado que se acidentou em serviço (art. I2O da Lei no 8.213/9I). Precedente desta Corte. 3. A empresa cujo empregado morreu em acidente de trabalho é parte legítima passiva em ação de regresso proposta pelo INSS. Precedente do STJ. 4. Como as provas juntadas aos autos comprovam que a Apelante agiu com culpa e nem ela mesma, em sua apelação, nega que tenha sido negligente, é de se entender que deva ressarcir o INSS pelo que a autarquia teve que pagar a título de pensão por morte aos filhos do empregado da empresa que 
se acidentou em serviço. 5. Nega-se provimento à apelação. [Apelação Civel 1999.38.00.021910-o/MG; Relatora Desembargador Federal Maria Isabel Gallotti Rodrigues; $6^{\text {a }}$ Turma; julgado em 29/07/2005, publicado em DJ p.79 de I7/IO/2005]. (BRASIL, 2005C)

Nos julgados do TRF da $2^{\text {a }}$ Região, destaca-se a articulação entre a Lei previdenciária e o art. 927 do Código Civil, além da importância das NRs, especificamente na construção civil:

INSS. Ação regressiva. Acidente de trabalho. Normas de segurança do trabalho não observadas. Art. 20 da Lei no 8.213/9I. Prescrição. Art. 206, $3^{\circ}$, V, do Código Civil. I. Não se aplica a regra de imprescritibilidade, prevista no art. $37, \$ 5^{\circ}$, da Lei Maior, quando o caso não se refere a pedido de ressarcimento em face de agentes públicos, em razão de ilícitos por eles praticados. A imprescritibilidade é exceção e não pode ser interpretada de forma ampliativa, para abarcar hipóteses não previstas expressamente pela norma. 2. No caso o INSS ajuizou ação contra empresa, para obter ressarcimento dos valores pagos a título de auxílio-doença e auxílio acidente, nos termos do art. I2O da Lei no 8.213/9I. Alega que a pessoa jurídica ré teria desobedecido as normas de segurança do trabalho, o que deu ensejo ao acidente que vitimou o segurado da Previdência Social. Entretanto, não foi observado o prazo prescricional de três anos, previsto no art. 206, $3^{\circ}$, V, do Código Civil, pois a demanda é de ressarcimento, fundada nos artigos I86 e 927 do CC, e art. I2O da Lei no 8.213. 3. A sentença resolveu adequadamente a questão, ao assinalar que "o prazo de 3 (três) anos estipulado pelo art. 206 do Código Civil refere-se à prescrição do próprio fundo de direito". 4. Reforma-se a sentença apenas no que tange à condenação do INSS nas custas processuais, tendo em vista a isenção legal. 5. Remessa e apelo parcialmente providos. [Apelação Cível 472433. Processo: 2008.50.0I.0II57I-2 UF:RJ, Relator Desembargador Federal Guilherme Couto; $6^{\mathrm{a}}$ Turma Especializada; julgado em I2/O7/2OIO]. (BRASIL, 2OIOC) 
Administrativo. INSS. Ação regressiva de cobrança. Benefício de pensão por morte acidentária. Responsabilidade solidária das rés. Negligência. Descumprimento de normas de segurança. Ressarcimento com gastos decorrentes de concessão de benefício. Constituição de capital. Trata-se de ação regressiva acidentária, de rito ordinário, ajuizada pelo INSS em face de TARGA ENGENHARIA LTDA, e ALVES E PEREIRA CONSTRUÇÕES E SERVICOS LTDA, objetivando o ressarcimento, de todos os gastos já efetuados decorrentes da concessão dos benefícios previdenciários NB I42.666.646-I e I42.I78.394-8, sustentando que concedeu pensões em razão morte acidentária do segurado Josemar da Silva. - Inicialmente, quanto as preliminares arguidas, em sede de contrarrazões, pela Ia apelada, no sentido de não conhecer do recurso, por ter deixado o INSS de atacar a sentença no ponto em que exonerou de responsabilidade Targa Engenharia Ltda, bem como de ilegitimidade passiva ad causam, rejeito a segunda, forte na fundamentação da decisão primária verbis - Rejeito a preliminar de ilegitimidade passiva ad causam formulada pela $\mathrm{I}^{\mathrm{a}}$ ré. O art. I2O da Lei no $8.2 \mathrm{I3}$, de I99I, determina que a autarquia previdenciária proponha ação em face dos responsáveis pelo acidente do trabalho, e não necessariamente em face apenas do empregador. Sendo assim, o empregador pode ser responsabilizado isoladamente ou, ainda, em conjunto com o tomador de serviços se se considera que este também é responsável pelo acidente. Na espécie, era a $I^{\mathrm{a}}$ ré a dona da obra em que se acidentou o empregado da $2^{\mathrm{a}}$ ré. Nessas condições, tinha também o dever de prevenir e evitar o acidente do trabalho - bem como a primeira, sinalando-se, que, cuidando-se de responsabilidade civil solidária, de caráter unitário, as razões recursais, passe-se o truísmo, dimanam efeitos sobre os envolvidos, restando inócua a argumentação, calcada em terceirização, vez que esta não tem o condão de eximir aqueles que de alguma forma contribuíram para o evento lesivo, o que deságua, portanto, no inacolhimento das questões prévias. Há que se estabelecer, neste diapasão, se há, ou não nexo de causalidade direto, ou indireto, entre o evento danoso, e as condutas da parte ré, in casu, de caráter 
omissivo, aquilatando-se se a lesão ocorrida guarda nexo lógico com este comportamento, de molde a se aferir qual o fato determinante do incidente, se no caso delineado, se o da vítima, ou das sociedades, que tiveram a melhor oportunidade, ou seja, a conduta melhor e mais eficiente de evitar o dano, qual a causa determinante, pelo que mesmo que a vítima tenha se mostrado imprudente, ou negligente, a sua culpa restara excluída, não se cogitando de concorrência de culpa, preponderando a conduta de terceiro, pois a se configurar como culpa grave necessária e suficiente. Diante do panorama probatório, concluo, efetivamente, que o Juízo a quo deixou de avaliar corretamente as provas dos autos, na medida que, a uma, deixou a segunda apelada de comprovar que o Sr. Josemar Silva, participou de treinamento, sendo inclusive multada por tal falha, sendo insuficiente a presença no campo de obras de supervisor responsável, que não atuou, como visto, de forma efetiva, conforme acima constatado do Relatório de Fiscalização do Ministério do Trabalho e Empregos; e a duas, apesar do vitimado se encontrar com alguns equipamentos de segurança, segundo testemunhas, e tê-los usado de forma imprecisa, não ficou comprovado noutro giro que alguns itens essenciais para sua segurança, tal como, guarda-corpo, andaimes adequados, conforme exigidos pela NR $\mathrm{n}^{\circ} \mathrm{I} 8$, mais precisamente I8.I3.I, que trata-se de instalação de proteção coletiva onde houver risco de queda de trabalhadores ou de projeção e materiais, bem como o treinamento exigido, restando, a meu juízo, comprovada a negligência das rés, pelo que prepondera, neste contexto, as condutas da parte ré, em detrimento do comportamento da vítima, o que conduz ao acolhimento do pleito autoral. No que concerne à constituição de capital, sua obrigatoriedade está definida pela Súmula 313/STJ - Em ação de indenização, procedente o pedido, é necessária a constituição de capital ou caução fidejussória para a garantia de pagamento de pensão, independentemente da situação financeira do demandado. -, inexistindo qualquer particularidade, a alijar a incidência do verbete similar, atraindo-se a regra do artigo $475-\mathrm{Q}$ 
do CPC. - Remessa Necessária e recurso providos. [Apelação/ Reexame Necessário 536808. Proc. 2009.5I.0I.01387-92RJ. Relator Desembargador Federal Poul Erik Dyrlund; $8^{\mathrm{a}}$ Turma Especializada; julgado em 08/O2/20I2; publicada em E-DJF2R, p. 355/356, de I6/O2/2OI2]. (BRASIL, 2OI2b)

Segue julgado do TRF da $3^{\text {a }}$ Região, que aponta aspecto processual do prazo prescricional para o ajuizamento da ação regressiva pelo INSS:

Agravo legal. Decisão monocrática. CPC, art. 557. Ação regressiva. INSS. Acidente de trabalho. Ressarcimento dos valores dispendidos para pagamento de auxílio doença e aposentadoria por invalidez. Normas de segurança do trabalho não observadas. Prazo prescricional aplicável à espécie. Trienal. Art. 206, $\$ 3^{\circ}$, do Código Civil. Recurso desprovido. I. A imprescritibilidade prevista no artigo 37, §5이 da Constituição Federal, refere-se ao direito da Administração Pública de obter o ressarcimento de danos ao seu patrimônio decorrentes de atos de agentes públicos, servidores ou não. Tal hipótese é taxativa e não pode ser ampliada com o escopo de abarcar a ação de reparação ajuizada pelo Instituto Nacional do Seguro Social, cuja natureza é nitidamente civil. 2. Também por este motivo - pela natureza civilista do direito buscado em juízo - incabível a pretensão de aplicar-se à espécie o prazo prescricional de cinco anos previsto na legislação previdenciária. Conclui-se, portanto, que, nos termos do art. 206, $\S 3^{\circ}$, V, do Código Civil, o lustro prescricional incidente na hipótese dos autos é de três anos. 3. Tendo sido o benefício acidentário concedido em novembro de 2005 e o presente feito ajuizado somente em julho de 20Io, de rigor o reconhecimento da prescrição da pretensão autoral. Precedentes. 4. Se a decisão agravada apreciou e decidiu a questão de conformidade com a Lei processual, nada autoriza a sua reforma. 5. Agravo legal desprovido. [Apelação Cível - 1676274. Processo 0003024-I7.2010.4.03.6127; Relatora Juíza Convocada Raquel Perrini; ${ }^{\mathrm{a}}$ Turma; julgado em 07/02/2OI2]. (BRASIL, 2012f) 
Do TRF da $4^{\mathrm{a}}$ Região, o destaque é para a indiferença patronal no cuidado às condições perigosas de trabalho:

Civil e previdenciário. Acidente de trabalho. Ação regressiva do INSS contra o empregador. Art. I20 da Lei no 8.213/9I. Dever do empregador de ressarcir os valores despendidos pelo INSS em virtude da concessão de benefício previdenciário. Culpa concorrente do segurado não demonstrada. Responsabilidade da empresa quanto à adoção e observância das medidas de proteção à segurança do trabalhador. Constituição de capital. Descabimento. Apelos desprovidos. I. Demonstrada a negligência do réu quanto à adoção e fiscalização das medidas de segurança do trabalhador, tem o INSS direito à ação regressiva prevista nos arts. I2O, I2I e I9, caput e $\S$ I $^{\circ}$, da Lei nº 8.2I3/9I, sendo o meio legal cabível para a autarquia reaver os valores despendidos com a concessão de benefício previdenciário a segurado vítima de acidente de trabalho, bastando, para tanto, a prova do pagamento do benefício e da culpa da ré pelo infortúnio que gerou a concessão do amparo. 2. Não se acolhe o pedido do INSS de constituição de capital para o pagamento das parcelas vincendas. Segundo o art. 475-Q do CPC, a constituição de capital somente ocorre quando a dívida for de natureza alimentar. A hipótese em tela trata de ressarcimento, isto é, restituição, afastando o caráter alimentar das parcelas. Além disso, o segurado não corre o risco de ficar sem a verba alimentar, cujo pagamento é de responsabilidade da autarquia. 3. Apelos desprovidos. [Apelação Cível 50004I570.20II.404.7207 - SC. Relator Carlos Eduardo Thompson Flores Lenz; $3^{\mathrm{a}}$ Turma; julgado em I6/05/20I2]. (BRASIL, 20I2h)

Processo civil. Responsabilidade civil. Acidente do trabalho. Ação regressiva contra empregador. Art. I2O da Lei no 8.213/9I. Culpa exclusiva. Morte. Pensão. Constituição de capital. Art. 602 do CPC. I. Ainda que seja natural a existência de algum risco nas atividades laborais, isto não exime o empregador do dever de zelar pela segurança no trabalho, devendo estes, ao contrário, oferecer o menor risco possível 
a seus empregados, ainda mais quando produzem e lidam com explosivos na própria área da empresa. 2. Consta que a vítima teve livre acesso aquele local sem a devida sinalização - nem uma barreira física para proteger o acesso ao local extremamente perigoso e próximo às demais atividades da empresa - e que não foi impedido de transportar o material que lá se encontrava. Assim, não há que se falar em aplicação do artigo 158, incisos I e II da CLT posto que não seria o uso de EPI ou mesmo uma prévia autorização de seus superiores para trabalhar na área que evitaria o acidente. 3. Não procede o pedido de constituição de capital em relação às parcelas vincendas do benefício, pois a aplicação do artigo 475-Q do Código de Processo Civil destina-se à garantia de subsistência de pensionista. Como o embargante não está sendo condenado a um pensionamento e sim a um ressarcimento das despesas relativas ao pagamento do benefício de pensão por morte, a beneficiária não corre risco de ficar sem a verba alimentar, cujo pagamento é de responsabilidade do INSS. 4. Não há como configurar explicitamente a solidariedade neste acidente em que a vítima não recebeu instruções específicas sobre a periculosidade do local dos explosivos nem teve uma fiscalização efetiva de seu superior, além de manter explosivo em local de livre acesso sem a devida sinalização nem qualquer barreira física. 5. Tendo o acórdão embargado afastado o reconhecimento de culpa por imprudência da vítima que resolveu incinerar restos de explosivos que estavam estocados no pátio da empresa sem prévia autorização de seus superiores, posto que caberia a empregadora tomar as medidas necessárias e suficientes para impedir o acesso ao local perigoso, prejudicado está o apelo da Nitro Prill Bombeamento de Explosivos Ltda. 6. Embargos de declaração parcialmente providos para afastar a determinação de constituição de capital ou caução fidejussória para garantia do recebimento das prestações vincendas e corrigir a parte dispositiva da decisão embargada de "dar provimento à apelação" para "julgar prejudicada a apelação da Nitro Prill 
Bombeamento de Explosivos Ltda." Embargos de Declaração em Apelação Civel. Processo 5000589-88.20II.404.7204-SC. Relator Carlos Eduardo Thompson Flores Lenz; $3^{\mathrm{a}}$ Turma; julgado em 25/O4/2OI2]. (BRASIL, 2OI2i)

Finalmente, os julgados do TRF da $5^{\text {a }}$ Região indicam a importância de laudos de auditores fiscais do trabalho como prova decisiva para a condenação da empresa negligente:

Civil e previdenciário. Ação regressiva. Pagamento de benefício decorrente de acidente de trabalho. Normas de segurança. Negligência do empregador. Ressarcimento devido. Constituição de capital. Não cabimento. I. A teor do art. I2O da Lei $n^{\circ}$ 8.213/9I, "nos casos de negligência quanto às normas padrão de segurança e higiene do trabalho indicados para a proteção individual e coletiva, a Previdência Social proporá ação regressiva contra os responsáveis." 2. Hipótese em que o Relatório de Investigação de Acidente de Trabalho Fatal, elaborado por Auditores Fiscais do Trabalho/RN, cuja presunção de veracidade e legitimidade não foi elidida pela empresa, demonstra as circunstâncias fáticas do acidente que causou a morte de um empregado, confirmando a negligência da demandada quanto às normas de segurança do trabalhador, razão pela qual deve ser mantida a sentença que a condenou ao ressarcimento dos valores pagos pelo INSS, a título de pensão por morte, à viúva do falecido. 3. Incabível a constituição de capital, nos termos do art. 475-Q do CPC, uma vez que os valores ressarcidos não configuram verba de caráter alimentar. 4. Há que ser corrigido o erro material contido no dispositivo da sentença, a fim de que conste como titular do benefício Milene Diogo Pereira de Lima, em vez de "Clotildes André de Lima". [Apelações improvidas. Erro material corrigido. Apelação Cível 506962/RN Proc. 200784000080442 Relator Desembargador Federal Luiz Alberto Gurgel de Faria; $3^{\text {a }}$ Turma; julgado em 26/04/2012]. (BRASIL, 20I2j)

Civil e previdenciário. Apelação cível e remessa oficial. Acidente de trabalho. Competência da Justiça Federal. Prescri- 
ção. Não configuração. Inexistência de cerceamento de defesa. Inobservância das regras de proteção e segurança do trabalhador. Pagamento de benefício decorrente de acidente. Ação regressiva do INSS. Procedência. Recursos improvidos. I. As ações regressivas indenizatórias nas quais o INSS postula indenização, com fundamento no art. I2O da Lei $n^{\circ}$ 8.213/9I, a competência para conhecer e julgar a demanda é da Justiça Federal. 2. Quanto à prescrição, tem-se adotado o entendimento de que, em tais casos, aplica-se a prescrição trienal do art. 206, parágrafo $3^{\circ}$, V do Código Civil. Dessa forma, tendo o acidente ocorrido em 09.Io.2006, não há que se falar em prescrição, vez que a presente ação foi ajuizada em 22.09.2009. 3. A contribuição exigida das empresas a título de seguro acidente de trabalho (SAT) faz parte da contribuição social disposta no art. 195 da CF/88, não havendo a exclusão da responsabilidade de indenizar, quando incorrer em dolo ou culpa. Interesse de agir do INSS caracterizado. 4. Nos termos do art. I2O da Lei no 8.213/9I, a Previdência Social proporá ação regressiva contra os responsáveis nos casos de negligência quanto às normas padrão de segurança e higiene do trabalho indicado para a proteção individual e coletiva dos trabalhadores. 5. No caso dos autos, o laudo técnico realizado pela Delegacia Regional do Trabalho comprovou as circunstâncias e o modo como ocorreu o acidente que ocasionou a amputação traumática do antebraço direito do empregado, restando, portanto, incontestável a negligência da empresa quanto à observância e fiscalização das normas de segurança do trabalho para proteção de seus trabalhadores, além do nexo causal entre a sua omissão e o dano ocorrido. 6. Uma vez demonstrada a omissão da Empresa quanto à observância das normas de segurança de trabalho, deve a mesma ressarcir o INSS pelos pagamentos efetuados à filha do empregado falecido, a título de pensão por morte acidentária. 7. Apelação e remessa oficial a que se nega provimento. [Apelação/Reexame Necessário I9634/CE. Proc. 20098Iooor27540, Relator Desembargador Federal Manoel Erhardt; I ${ }^{\mathrm{a}}$ Turma, julgado em 03/05/20I2]. (BRASIL, 2OI2l) 
O posicionamento do STJ sobre a questão realça o dispositivo legal no reconhecimento da ação acidentária como instrumento adequado para o INSS perseguir os responsáveis para o ressarcimento dos gastos decorrentes de acidentes de trabalho:

Previdenciário e processo civil. Benefício previdenciário decorrente de acidente de trabalho. Ação regressiva proposta pelo INSS em desfavor do empregador. Art. I2O da Lei no 8.213/9I. Denunciação da lide à empresa tomadora de serviço. Impossibilidade de condenação exclusiva do denunciado. Recurso especial desprovido. I. Em face dos princípios da economia e finalística processual, a jurisprudência do STJ tem atenuado os rigores técnicos para permitir que o denunciado, quando tenha aceitado a denunciação e contestado o pedido, assuma a condição de litisconsorte do denunciante e, diante dessa situação, possa ser diretamente e solidariamente condenado perante o autor da demanda principal. 2. Contudo, não se admite a denunciação da lide com fundamento no art. 70, III do CPC se o denunciante objetiva eximir-se da responsabilidade pelo evento danoso, atribuindo-o com exclusividade a terceiro, como no presente caso. 3. Recurso Especial desprovido. [REsp II8026I/ RS Proc. 2010/0023II8-3, Relator Ministro Napoleão Nunes Maia Filho; $5^{\text {a }}$ Turma, julgado em I9/o8/20IO, publicado em DJe I3/og/20IO, RIOBTP vol. 257, P. I6I.] (BRASIL, 2OIOC)

A respeito de fiscalização pública das condições de trabalho com a finalidade de evitar negligências, tal tarefa não se limita aos auditores fiscais do Ministério do Trabalho e Emprego, mas também à vigilância do SUS, conforme consta do art. 6º, I, c, da Lei no 8.080/90. Além disso, cabe ao poder público acompanhar os ambientes de trabalho e a adoção de medidas preventivas, conforme dispõe a Lei no 8.213/91:

Art. II9. Por intermédio dos estabelecimentos de ensino, sindicatos, associações de classe, Fundação Jorge Duprat Figueiredo de Segurança e Medicina do Trabalho - FUNDACENTRO, órgãos públicos e outros meios, serão promovidas regular- 
mente instrução e formação com vistas a incrementar costumes e atitudes prevencionistas em matéria de acidente, especialmente do trabalho. (BRASIL, I99Ia)

Diante dessas reflexões e dos posicionamentos jurisprudenciais, pode-se concluir que a concessão, administrativa ou por via judicial, do auxílio-acidente decorrente de acidente do trabalho em sua acepção mais ampla, e considerando a existência de incapacidade parcial e permanente mínima, é suficiente para que a administração pública ajuíze ação regressiva contra as empresas empregadoras, ou eventualmente ex-empregadoras, dos beneficiários do auxílio-acidente. 